\title{
A randomized, multi-central, controlled study of patients with hepatitis B e antigen-positive chronic hepatitis B treated by adefovir dipivoxil or adefovir dipivoxil plus bicyclol
}

\author{
Wen Xie • Guangfeng Shi • Hongfei Zhang • \\ Guiming Zhao $\cdot$ Zujiang Yu $\cdot$ Zhenwei Lang \\ Hong Zhao $\cdot$ Jie Yan $\cdot$ Jun Cheng
}

Received: 28 January 2011/ Accepted: 20 June 2011/Published online: 20 July 2011

(c) The Author(s) 2011. This article is published with open access at Springerlink.com

\begin{abstract}
Objective To evaluate the efficacy and safety profiles of patients with hepatitis $\mathrm{B}$ e antigen ( $\mathrm{HBeAg}$ )-positive chronic hepatitis $\mathrm{B}(\mathrm{CHB})$ treated with adefovir dipivoxil (ADV) or ADV plus bicyclol, and to optimize the treatment strategy for CHB patients.

Patients and methods A total of 250 patients with HBeAgpositive $\mathrm{CHB}$ were randomized to ADV plus bicyclol combination group and ADV monotherapy group. The patients in the ADV plus bicyclol combination therapy group $(n=125)$ received ADV $10 \mathrm{mg}$ orally q.d. and bicyclol $25 \mathrm{mg}$ orally t.i.d. for 48 weeks, and those in the ADV monotherapy group $(n=125)$ were administered ADV $10 \mathrm{mg}$ orally q.d. alone for 48 weeks. The serum aminotransferases (ALT/AST), $\mathrm{HBV}$ DNA, $\mathrm{HBe} \mathrm{Ag} / \mathrm{HBe} \mathrm{Ab}$, and liver biopsy were conducted before and after therapy.
\end{abstract}

W. Xie $\cdot$ Z. Lang $\cdot$ H. Zhao $\cdot$ J. Yan $\cdot$ J. Cheng $(\varangle)$

Liver Center, Beijing Ditan Hospital,

Capital Medical University, 100015 Beijing, China

e-mail: jun.cheng.ditanhospital@gmail.com

G. Shi

Department of Infectious Diseases, Huashan Hospital,

Fudan University, Shanghai, China

H. Zhang

Department of Pediatric Hepatology,

The 302 Hospital of PLA, Beijing, China

G. Zhao

Department of Hepatology,

Tianjin Municipal Hospital of Infectious Diseases,

Tianjin, China

Z. Yu

Department of Infectious Diseases,

First Hospital, Zhengzhou University, Zhengzhou, China
Results The serum aminotransferase levels were decreased significantly in both groups. The serum aminotransferase level in ADV plus bicyclol combination therapy group decreased greater than that in ADV monotherapy group $(P<0.01)$. The virological response rate in ADV plus bicyclol combination therapy group was not significantly different from that in ADV monotherapy group $(P>0.05)$. After treatment for 48 weeks, the Knodell necroinflammatory score of the two groups were all alleviated significantly, and the Knodell score in the combination group was significantly lower than that in the ADV monotherapy group $(P<0.05)$. There were no remarkable adverse events probably related to the drug in this study. Conclusion Adefovir dipivoxil plus bicyclol combination therapy is a safe and superior treatment regimen for patients with $\mathrm{HBeAg}$-positive $\mathrm{CHB}$ when compared with ADV monotherapy.

Keywords Chronic hepatitis B - Adefovir dipivoxil · Bicyclol

\section{Introduction}

Chronic hepatitis B virus (HBV) infection is a major health problem worldwide [1]. Carriers of HBV have increased risk of developing cirrhosis, liver decompensation, and hepatocellular carcinoma (HCC) [2]. About $15-40 \%$ of the HBV carriers will develop serious liver diseases during their lifetime [3]. The chronic hepatitis B (CHB) is becoming a worldwide burden because the pathologic mechanism is complex and it is difficult to eradicate the HBV completely [4]. Effective treatments are required to prevent progression of $\mathrm{CHB}$ to cirrhosis, $\mathrm{HCC}$, and death [5]. Monotherapy using interferon (IFN) or nucleos(t)ide 
(NUC) analogs has strong clinical evidence [6, 7]. But only a small percentage of $\mathrm{HBeAg}$-positive $\mathrm{CHB}$ patients experienced $\mathrm{HBeAg}$ loss or seroconversion after 1 year therapy with IFN/pegylated IFN. Short-term treatment of CHB patients with NUC is insufficient and prolonged therapy may result in high cost and drug resistance [8, 9]. The notion of combination therapy for $\mathrm{CHB}$ treatment has been previously examined, yielding inconclusive results [10]. It is an urgent task to have better strategies for the future treatment of patients with $\mathrm{CHB}$.

The final goal of antiviral therapy for patients with $\mathrm{CHB}$ is to reduce the incidence of end-stage liver diseases, and increase the chance of living a longer, better life [11]. For this purpose, the recent goal was to improve the liver histology with either IFN/PEG-IFN or NUC [12]. Antiviral therapy with either IFN/PEG-IFN or NUC has shown only a partial improvement in liver histology [13]. Adefovir dipivoxil (ADV) is an oral prodrug of adefovir, an analog of adenosine monophosphate, widely used in the clinical treatment of $\mathrm{CHB}$ patients [14]. The active intracellular metabolite, adefovir diphosphate, inhibits HBV DNA polymerase at levels much lower than those needed to inhibit the human DNA polymerases [15]. Studies in vivo and in vitro showed that adefovir could significantly inhibit the replication of HBV DNA in both wild type and YMDD mutant type [16].

For hepatologists, especially in East Asian countries, liver protectant drug played an important role in the treatment of CHB patients for a long time before antiviral therapy was made available [17]. Accumulated clinical evidence demonstrated significant histological improvement after the liver protectant drug therapy [18]. Bicyclol is $4,4^{\prime}$-dimethoxy-5, 6, 5', 6'-dimethylene-dioxy-2, 2'dicarboxylate biphenyl, a widely used liver protectant drug in China and other countries [19]. Although the mechanism of action of bicyclol is largely unknown, its anti-liver injury, anti-liver inflammation, and anti-liver fibrosis effects have been well established in the recent years [20]. Both experimental and clinical studies have shown that bicyclol can significantly reduce the experimental liver injury and liver fibrosis, and has significant antiinflammatory activity [21]. The mechanism of action is closely related to the elimination of free radicals, protection of membrane and mitochondrial functions, suppression of oxidative damage, induction of vivo antioxidants, and inhibition of the serum $\mathrm{TNF} \alpha$, and inflammatory cytokines that were induced by chronic carbon tetrachloride injury [22]. Recent studies indicate that bicyclol not only promotes Th1-type cytokine-mediated immune responses but also downregulates Th2-type cytokine-mediated immune responses [23]. Bicyclol can reduce liver inflammation and protect liver from cell injury, decrease collagen synthesis and secretion, and promote the degradation and absorption of collagen. Therefore, it can inhibit the formation and development of liver fibrosis [24].

Pilot antiviral drug plus liver protectant drug have been proved to be effective for the treatment of $\mathrm{CHB}$, but there is no well-designed clinical study conducted till now. To establish strong evidence for the antiviral plus liver protectant drug for CHB patients, we evaluated the efficacy and safety profiles by combining ADV with liver protectant drug (bicyclol) on HBeAg-positive CHB patients in China, and the results, especially the improvement in histology, are obviously promising.

\section{Patients and methods}

\section{Patient population}

Altogether 250, including 182 male and 68 female patients with $\mathrm{HBeAg}$-positive $\mathrm{CHB}$ were enrolled in this study. Average age of all patients was 35.4 years (18-60 years), who had been diagnosed with $\mathrm{CHB}$ for $\geq 6$ months. All the patients were IFN/PEG-IFN or NUC treatment naive. The baseline serum alanine aminotransferase (ALT) level was 2-10 times of the upper limit of the normal (ULN) for all the patients. Serum HBsAg and HBV DNA continued to be positive for $>6$ months. All the patients were $\mathrm{HBeAg}$ positive and -negative, with a serum HBV DNA level of $\geq 1.0 \times 10^{6}$ copies $/ \mathrm{mL}$, and none had concomitant other categories hepatitis virus infection. A total bilirubin level was $\leq 3.0 \mathrm{mg} / \mathrm{dL} \quad(50 \mu \mathrm{mol} / \mathrm{L})$ and relatively stable recently. Simultaneously, drug-induced hepatitis, alcoholic hepatitis, and autoimmune hepatitis were excluded. A total of 250 patients were randomly assigned to ADV monotherapy and ADV plus bicyclol combination therapy groups.

\section{Therapeutic schedule}

Patients in the monotherapy group were treated with $10 \mathrm{mg}$ of ADV (Tianjin Institute of Pharmaceutical Research Pharmaceutical Company, Limited, Tianjin, China) ( $n=125$ ), and patients in the combination therapy group with $10 \mathrm{mg}$ of ADV plus $75 \mathrm{mg}$ (25 mg, t.i.d.) of bicyclol (Beijing Union Pharmaceutical Factory, Beijing, China) ( $n=125)$ daily, both for 48 weeks.

Other antiviral drugs and liver protectant drugs were not allowed during the therapy.

Liver biochemistry and serological markers of HBV

The serum biochemistry parameters, including ALT and AST, were determined every 12 weeks. HBV serological markers, including $\mathrm{HBsAg}$, anti-HBs, $\mathrm{HBeAg}$, and anti- 
$\mathrm{HBeAg}$, were determined by a microparticle enzyme immunoassay. Reagents used in the determination of liver biochemistry and HBV serology were purchased from Abbott Laboratories (USA). Real-time PCR was performed to quantitatively detect the serum HBV DNA using the PG HBV FQ-PCR kit (Shenzhen PG Biotech). The lower limit detection of this system was 1,000 copies $/ \mathrm{ml}$.

Liver pathological examination

\section{Liver biopsy}

Liver biopsy was performed using a16 $\mathrm{G}$ needle, requiring hepatic tissue $\geq 1 \mathrm{~cm}$, including four and more than four portal areas. Processing of the tissue and preparation of microscopic sections were performed conventionally. Thickness of the films was $4 \mu \mathrm{m}$, and they were stained by hematoxylin-eosin, silver impregnation method, and Masson trichrome.

\section{Evaluation of liver histopathology}

The pathological expert was blinded to all sections at baseline and 48 weeks of treatment for evaluating liver histology activity index (HAI), necroinflammation, and fibrosis scores according to the Knodell necroinflammatory score system [25].

\section{Statistical analysis}

All analyses were performed using SPSS version 16.0 (SPSS Inc, USA). The demographics of patients and virological response were compared by the Student's $t$ test for continuous data and Chi-square test for dichotomous data. A value of $P<0.05$ was considered statistically significant.

\section{Ethical issue}

A consent form was signed by each patient before enrollment to the study.

\section{Results}

Eight patients withdrew from the study during 48 weeks of treatment. Of the remaining 242 patients, 122 patients received $10 \mathrm{mg}$ of ADV plus $75 \mathrm{mg}$ of bicyclol daily (combination therapy group), and 122 patients received $10 \mathrm{mg}$ of $\mathrm{ADV}$ alone (monotherapy group). There were no significant differences in the demographic or HBV disease characteristics between the two groups (Table 1).
Table 1 Comparison of baseline characteristics of patients in ADV monotherapy and ADV plus bicyclol combination therapy groups

\begin{tabular}{lll}
\hline & $\begin{array}{l}\text { Combination } \\
\text { therapy } \\
(n=125)\end{array}$ & $\begin{array}{l}\text { Monotherapy } \\
(n=125)\end{array}$ \\
\hline Age & $35.2 \pm 10.2$ & $35.7 \pm 11.3$ \\
BMI $\left(\mathrm{kg} / \mathrm{m}^{2}\right)$ & $21.5 \pm 2.8$ & $20.8 \pm 3.1$ \\
Gender: female $(\%)$ & $33 / 125(26.4)$ & $35 / 125(28.0)$ \\
Time since diagnosis $\geq 2$ years $(\%)$ & $61 / 125(48.8)$ & $59 / 125(47.2)$ \\
HBV DNA, $\log _{10}$ copies/mL & $7.0 \pm 1.3$ & $6.9 \pm 1.0$ \\
ALT $(\mathrm{U} / \mathrm{L})$ & $153.4 \pm 68.8$ & $146.5 \pm 59.3$ \\
ALT range $(\%)$ & & \\
2 to $\leq 5 \times \mathrm{ULN}$ & $76 / 125(60.8)$ & $75 / 125(57.6)$ \\
$>5 \times \mathrm{ULN}$ & $49 / 125(39.2)$ & $53 / 125(42.4)$ \\
\hline
\end{tabular}

No significant differences were observed for age, BMI, gender, time since diagnosis, HBV DNA viral load, ALT levels of patients in ADV monotherapy compared with ADV plus bicyclol combination therapy groups

\section{Biochemical responses}

Serum ALT levels of patients at 24 and 48 weeks of treatment in both ADV plus bicyclol combination therapy group $(39.8 \pm 25.6$ vs. $153.4 \pm 68.8 ; 30.3 \pm 14.1$ vs. $153.4 \pm 68.8)$ and ADV monotherapy group $(66.1 \pm 42.7$ vs. $146.5 \pm 59.3 ; 46.4 \pm 30.3$ vs. $146.5 \pm 59.3)$ were significantly decreased when compared with the baseline levels, respectively (Table 2; Fig. 1$)(P<0.01,<0.01)$. Serum AST levels of patients at 24 and 48 weeks of treatment in both ADV plus bicyclol combination therapy group $(46.6 \pm 26.9$ vs. $136.3 \pm 50.7 ; 40.8 \pm 20.2$ vs. $136.3 \pm 50.7)$ and ADV monotherapy group (67.9 \pm 38.7 vs. $132.2 \pm 50.7 ; 48.2 \pm 27.5$ vs. $132.2 \pm 50.7)$ were significantly decreased compared with baseline levels, respectively (Table 2 ; Fig. 2$)(P<0.01)$. At the 24 and 48 weeks of therapy, both ALT and AST levels of patients in combination group $(39.8 \pm 25.6$ vs. $66.1 \pm 42.7$; $30.3 \pm 14.1$ vs. $46.4 \pm 30.3$ ) were significantly lower than that of patients in the monotherapy group $(46.6 \pm 26.9$ vs. $67.9 \pm 38.7 ; 40.8 \pm 20.2$ vs. $48.2 \pm 27.5)$, respectively (Table 2; Figs. 1, 2) $(P<0.01, P<0.01)$.

ALT normalization rates of patients in combination therapy group at 12, 24, 36, and 48 weeks $(48.4,64.8,70.5$, and $78.7 \%$ ) were significantly higher than that of patients in monotherapy group $(25.8,42.5,50.8$, and $60.0 \%)$, respectively (Table 3; Fig. 3) $(P<0.01)$. AST normalization rates of patients in combination therapy group at 12 , 24,36 , and 48 weeks $(44.3,59.0,63.9$, and $68.7 \%$ ) were significantly higher than that of patients in the monotherapy group (25.0, 40.0, 46.7, and 54.2\%), respectively (for week 12, 24, and 36, $P<0.01$; for week 48, $P<0.05$ ) (Table 3; Fig. 4). 
Table 2 Dynamic changes of ALT and AST levels during treatment $(x \pm s, \mathrm{U} / \mathrm{L})$

\begin{tabular}{lllll}
\hline & No. $(n)$ & Baseline & 24 weeks & 48 weeks \\
\hline ALT & & & & \\
Monotherapy & 120 & $146.5 \pm 59.3$ & $66.1 \pm 42.7$ & $46.4 \pm 30.3$ \\
Combination & 122 & $153.4 \pm 68.8$ & $39.8 \pm 25.6^{\mathrm{a}}$ & $30.3 \pm 14.1^{\mathrm{a}, \mathrm{b}}$ \\
AST & & & & \\
Monotherapy & 120 & $133.2 \pm 50.7$ & $67.9 \pm 38.7$ & $48.2 \pm 27.5$ \\
Combination & 122 & $136.3 \pm 50.7$ & $46.6 \pm 26.9^{\mathrm{a}}$ & $40.8 \pm 20.2^{\mathrm{a}, \mathrm{b}}$ \\
\hline
\end{tabular}

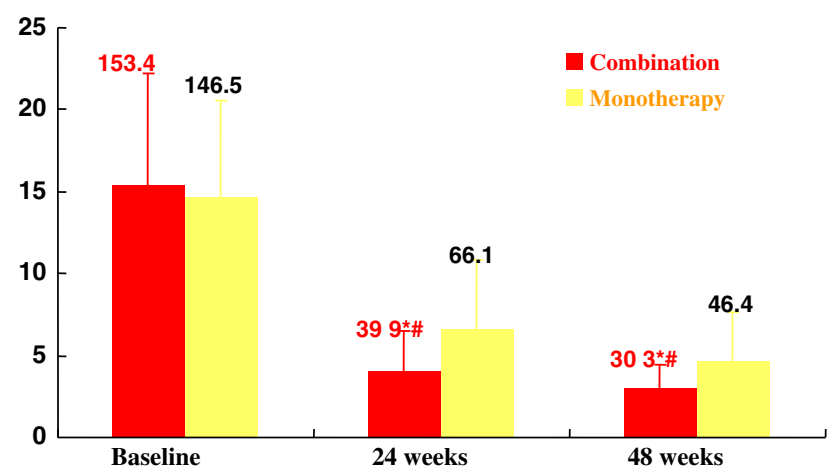

Fig. 1 Baseline average ALT level for patients in ADV monotherapy group is not significantly different to that of ADV plus bicyclol combination therapy group. At weeks 24 and 48 of treatment, ALT levels were significantly decreased for patients in both groups compared with that of baseline levels $(* P<0.01)$, ALT levels decreased more significantly in combination therapy group than that in monotherapy group, respectively $\left({ }^{\#} P<0.01\right)$

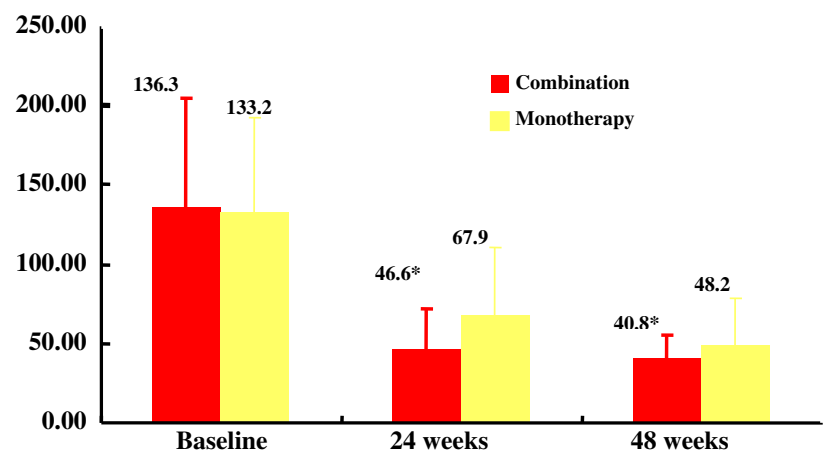

Fig. 2 Baseline average AST level for patients in ADV monotherapy group is not significantly different to that of ADV plus bicyclol combination therapy group. At weeks 24 and 48 of treatment, AST levels were significantly decreased for patients in both groups compared with that of baseline levels $(* P<0.01)$, AST levels decreased more significantly in combination therapy group than that in monotherapy group, respectively $\left({ }^{\#} P<0.01\right)$

Virological and immunological responses

At the end of treatment, the HBV DNA levels were found to be significantly decreased from $6.9 \pm 1.0 \log _{10}$ copies/ $\mathrm{mL}$ at baseline to $3.1 \pm 1.2 \log _{10}$ copies $/ \mathrm{mL}$ at week 48 for patients in the monotherapy group $(P<0.01)$, and from
$7.0 \pm 1.0$ to $3.3 \pm 1.2 \log _{10}$ copies $/ \mathrm{mL}$ for patients in the combination therapy group $(P<0.01)$. The HBV DNA levels, however, had no significant difference between the monotherapy group $\left(3.1 \pm 1.2 \log _{10}\right.$ copies $\left./ \mathrm{mL}\right)$ and the combination therapy group $\left(3.3 \pm 1.2 \log _{10}\right.$ copies $\left./ \mathrm{mL}\right)$ at week 48 (Table 3) $(P>0.05)$. At the end of treatment, percentages of patients with HBV DNA $\leq 1,000 \log _{10}$ copies/ $\mathrm{mL}, \mathrm{HBe} A g$ loss, and HBeAg seroconversion in monotherapy group $(31.7,25.8$, and $18.3 \%$, respectively) were not significantly different to that in the combination therapy group (34.4, 29.5 , and $20.5 \%$, respectively) (Table 3).

\section{Histological improvements}

Liver biopsy was performed twice in 87 patients, at baseline and after treatment at week 48 , with 45 patients in the ADV plus bicyclol combination therapy group and 42 patients in the ADV monotherapy group. Average Knodell necroinflammatory score was found to be significantly decreased from $7.0 \pm 3.0$ at baseline to $4.6 \pm 2.8$ at week 48 for patients in monotherapy group, and from $7.4 \pm 2.9$ at baseline to $3.5 \pm 2.0$ at week 48 for patients in combination therapy group $(P<0.01)$. After 48 weeks of treatment, Knodell necroinflammatory score reduction in combination therapy group was significantly greater than that in monotherapy group $(3.8 \pm 2.9$ vs. $2.4 \pm 2.3$, respectively) (Table 4) $(P<0.05)$.

Typical histology improvements were observed, for example in two cases, No. 1 and No. 2. Necroinflammatory degrees decreased significantly at the end of therapy (Figs. 5b, 6b) comparing with baseline (Figs. 5a, 6a), respectively.

\section{Safety profiles}

There were no serious adverse events during the course of this study. In 125 treated patients, 15 had $12.0 \%$ adverse events. In 125 patients from the ADV monotherapy group, 18 had $14.4 \%$ adverse events. The difference was not statistically significant. All the adverse events were nonspecific, including respiratory infections, lower limb pain, bleeding gums, rashes, diarrhea, insomnia, etc (Table 5). During therapy uncomfortable symptoms were almost relieved after symptomatic treatment. There was no 
Table 3 Comparison of ALT, AST normalization rates in two groups during treatment and virological responses in two treatment groups at 48 weeks

\begin{tabular}{|c|c|c|c|c|c|c|c|c|c|}
\hline \multirow[t]{2}{*}{ Group } & \multicolumn{3}{|c|}{ ALT normalization rates } & \multicolumn{3}{|c|}{ AST normalization rates } & \multicolumn{3}{|c|}{ Serological markers of $\mathrm{HBV}$ at 48 week } \\
\hline & 12 week & 24 week & 48 week & 12 week & 24 week & 48 week & $\begin{array}{l}\text { HBV DNA } \\
\leq 1,000 \\
\text { copies } / \mathrm{mL}\end{array}$ & $\begin{array}{l}\text { HBeAg } \\
\text { loss }\end{array}$ & $\begin{array}{l}\mathrm{HBe} A \mathrm{~g} \\
\text { seroconversion }\end{array}$ \\
\hline $\begin{array}{l}\text { Monotherapy } \\
\%(n)\end{array}$ & $\begin{array}{l}25.8 \\
\quad(31 / 120)\end{array}$ & $\begin{array}{l}42.5 \\
\quad(51 / 120)\end{array}$ & $\begin{array}{l}60.0 \\
\quad(72 / 120)\end{array}$ & $\begin{array}{l}25.0 \\
\quad(30 / 120)\end{array}$ & $\begin{array}{l}40.0 \\
\quad(48 / 120)\end{array}$ & $\begin{array}{l}54.2 \\
\quad(65 / 120)\end{array}$ & $\begin{array}{l}31.7 \\
\quad(38 / 120)\end{array}$ & $\begin{array}{l}25.8 \\
\quad(31 / 120)\end{array}$ & $\begin{array}{l}18.3 \\
(22 / 120)\end{array}$ \\
\hline $\begin{array}{l}\text { Combination } \\
\%(n)\end{array}$ & $\begin{array}{l}48.4 \\
\quad(59 / 122)^{\mathrm{a}}\end{array}$ & $\begin{array}{l}64.8 \\
\quad(79 / 122)^{\mathrm{a}}\end{array}$ & $\begin{array}{l}78.7 \\
(96 / 122)^{\mathrm{a}}\end{array}$ & $\begin{array}{l}44.3 \\
\quad(54 / 122)^{\mathrm{a}}\end{array}$ & $\begin{array}{l}59.0 \\
(72 / 122)^{\mathrm{a}}\end{array}$ & $\begin{array}{l}68.7 \\
\quad(83 / 122)^{b}\end{array}$ & $\begin{array}{l}34.4 \\
\quad(42 / 122)\end{array}$ & $\begin{array}{l}29.5 \\
\quad(36 / 122)\end{array}$ & $\begin{array}{l}20.5 \\
(25 / 122)\end{array}$ \\
\hline
\end{tabular}

${ }^{\text {a }}$ Compared to ADV monotherapy group, $P<0.01$

${ }^{\mathrm{b}} P<0.05$

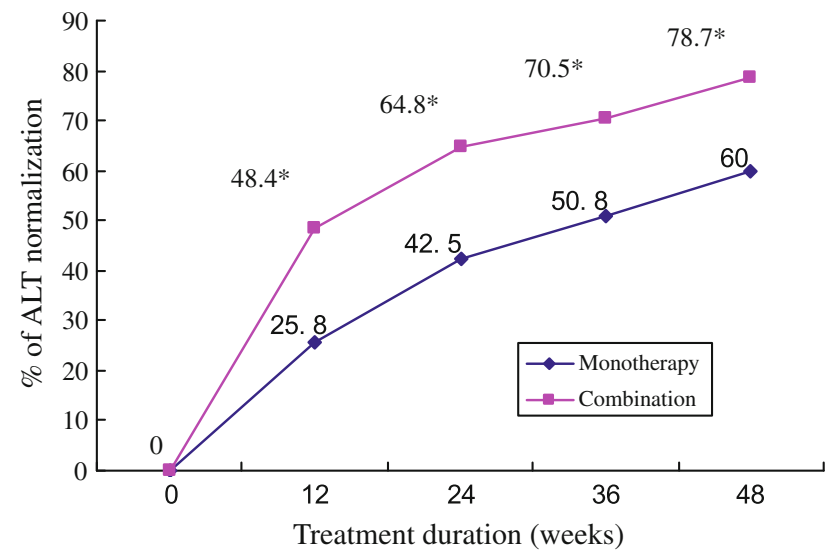

Fig. 3 Rates of ALT normalization at the weeks 12, 24, 36, and 48 of the treatment in patients of ADV plus bicyclol combination therapy group were significantly higher than that in ADV monotherapy group, respectively $(* P<0.01)$

incidence of study drugs being discontinued because of adverse events. No drug-related severe adverse events and laboratory abnormalities were observed. Renal function was checked during treatment, including serum creatinine and blood urea nitrogen. No significant differences were observed for creatinine and blood urea nitrogen levels at baseline and at 48 weeks therapy.

\section{Discussion}

Oral NUC is easily acceptable by the CHB patients for its convenience and few side effects [26]. After a short period of treatment, most of the patients were able to achieve undetectable HBV DNA. Although HBV DNA response is usually satisfied, histological improvement is quite limited [27]. To optimize histological improvement and look for long-term benefits for patients with $\mathrm{CHB}$, de novo combination therapy is one of the options. ADV is widely used in the clinical treatment of $\mathrm{CHB}$ patients. Domestic and foreign clinical trials showed that it decreased the serum HBV DNA and ALT levels, improved liver histology in both $\mathrm{HBeAg}$-positive and $\mathrm{HBeAg}$-negative patients with $\mathrm{CHB}$, and resulted in $\mathrm{HBeAg}$ seroconversion in $\mathrm{HBeAg}$ positive patients. Treatment has been found to be safe and well tolerated, with a low incidence of adverse events [28]. But ADV is usually used as monotherapy. Bicyclol is a liver protectant drug for patients with various liver diseases including viral hepatitis, drug-induced liver injuries, alcohol liver diseases, and autoimmune liver diseases in many countries [29]. Clinical studies demonstrated that bicyclol treatment for a year could achieve significant improvement in liver histology for various kinds of liver diseases [30]. For both ADV and bicyclol, monotherapy only could achieve limited liver histological improvement. It is thus reasonable to explore the combination therapy using ADV plus bicyclol for the treatment of CHB patients.

Bicyclol is a widely used liver protectant drug in China and other countries. Clinical trial was performed by double blind, randomized, and positive control or placebo method in multi-medical centers in China, using bicyclol $25 \mathrm{mg}$ thrice daily for 6 months demonstrating ALT AST normalization in $50 \%$ of the patients with chronic viral

Table 4 Comparison of Knodell necroinflammatory scores in two groups at 48 weeks of therapy

\begin{tabular}{|c|c|c|c|c|c|c|}
\hline \multirow[t]{2}{*}{ Group } & \multicolumn{3}{|c|}{ Necroinflammatory scores $(x \pm s)$} & \multicolumn{3}{|c|}{ Fibrosis scores $(x \pm s)$} \\
\hline & Baseline & At 48 weeks & Reduction & Baseline & At 48 weeks & Reduction \\
\hline Monotherapy & $7.0 \pm 3.0$ & $4.6 \pm 2.8^{\mathrm{a}}$ & $2.4 \pm 2.3$ & $1.6 \pm 0.91$ & $1.0 \pm 0.66$ & $0.5 \pm 0.2$ \\
\hline Combination therapy & $7.4 \pm 2.9$ & $3.5 \pm 2.0^{\mathrm{a}}$ & $3.8 \pm 2.9^{\mathrm{b}}$ & $2.0 \pm 1.0$ & $1.2 \pm 0.8$ & $0.7 \pm 0.3$ \\
\hline
\end{tabular}

${ }^{\text {a }}$ Compared to the baseline scores, $P<0.01$

b Compared to ADV monotherapy group, $P<0.05$ 


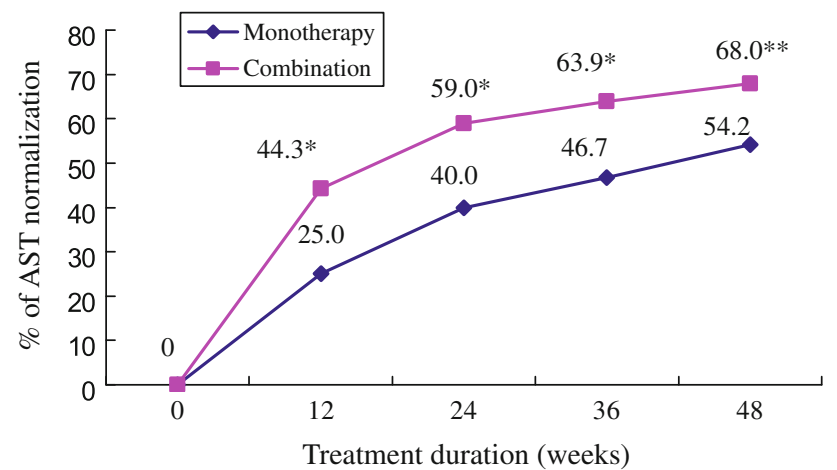

Fig. 4 Rates of AST normalization at weeks 12, 24, and 36 of the treatment in patients of ADV plus bicyclol combination therapy group were significantly higher than that in ADV monotherapy group, respectively $(* P<0.01)$. Rate of AST normalization at week 48 of the treatment in patients of ADV plus bicyclol combination therapy group is significantly higher than that in ADV monotherapy group ( $\left.{ }^{\#} P<0.05\right)$

Table 5 Comparison of adverse events incidence of patients in ADV monotherapy and ADV plus bicyclol combination therapy groups

\begin{tabular}{lll}
\hline & $\begin{array}{l}\text { Combination } \\
(15 / 125)\end{array}$ & $\begin{array}{l}\text { Monotherapy } \\
(18 / 125)\end{array}$ \\
\hline Respiratory infection & 5 & 6 \\
Lower limb pain & 3 & 5 \\
Bleeding gum & 3 & 3 \\
Rashes & 2 & 2 \\
Diarrhea & 1 & 1 \\
Insomnia & 1 & 1
\end{tabular}

No significant differences were observed in ADV monotherapy comparing with ADV plus bicyclol combination therapy groups hepatitis B and C. Eight articles reported the efficacy of the combination therapy of lamivudine plus bicyclol and lamivudine or bicyclol used alone [31]. The results are briefly summarized as follows: total of more than $200 \mathrm{CHB}$ patients enrolled in the trials were previously treated with lamivudine, some of them had already developed drug resistance to lamivudine because of YMDD development. The schedule of treatment was lamivudine $100 \mathrm{mg}$, q.d. plus bicyclol 25 or $50 \mathrm{mg}$, t.i.d. p.o. for 24 or 48 weeks. In general, at the end of combination therapy of lamivudine plus bicyclol, the effectiveness of anti-HBV DNA and negative of $\mathrm{HBeAg}$ were higher than lamivudine or bicyclol used alone, particularly the YMDD mutant, and relapse rate of virus markers was reduced. Two articles reported the therapeutic effect of IFNa-2b alone and in combination with bicyclol in CHB. In general, as compared to INFa-2b treatment alone, the combination of bicyclol with INFa-2b increased the improvement of the abnormal liver function and HBV-DNA negative, and reduced adverse reaction of INFa-2b.

To use ADV and bicyclol in combination therapy for CHB patient, one concern might be the drug-drug interaction, and its effects on treatment and safety profiles. From this trial, we did not observe more side effects in the combination therapy group than in ADV monotherapy group, indicating de novo combination therapy of these two drugs is safe. Because of the complexity of bicyclol function, the influence of the drug on ADV antiviral effect is yet to be elucidated. From the percentages of patients with HBV DNA $\leq 1,000 \log _{10}$ copies $/ \mathrm{mL}, \mathrm{HBe} A g$ loss, and $\mathrm{HBeAg}$ seroconversion at the end of therapy, there were no
Fig. 5 Necroinflammation and fibrosis scores of patient No. 1 were significantly improved after 48 weeks therapy

(b) compared with baseline (a) using ADV plus bicyclol

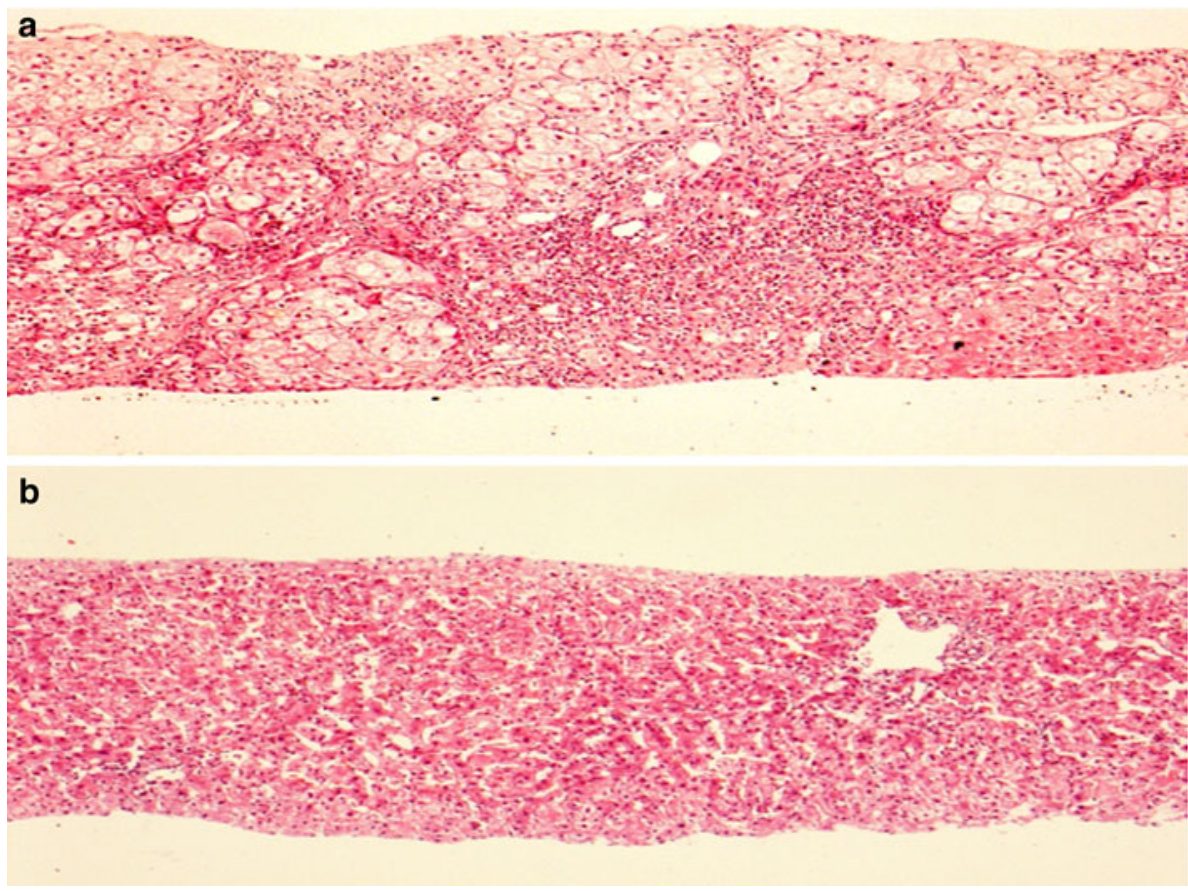


Fig. 6 Necroinflammation and fibrosis scores of patient No. 2 were significantly improved after 48 weeks therapy

(b) compared with baseline (a) using ADV plus bicyclol
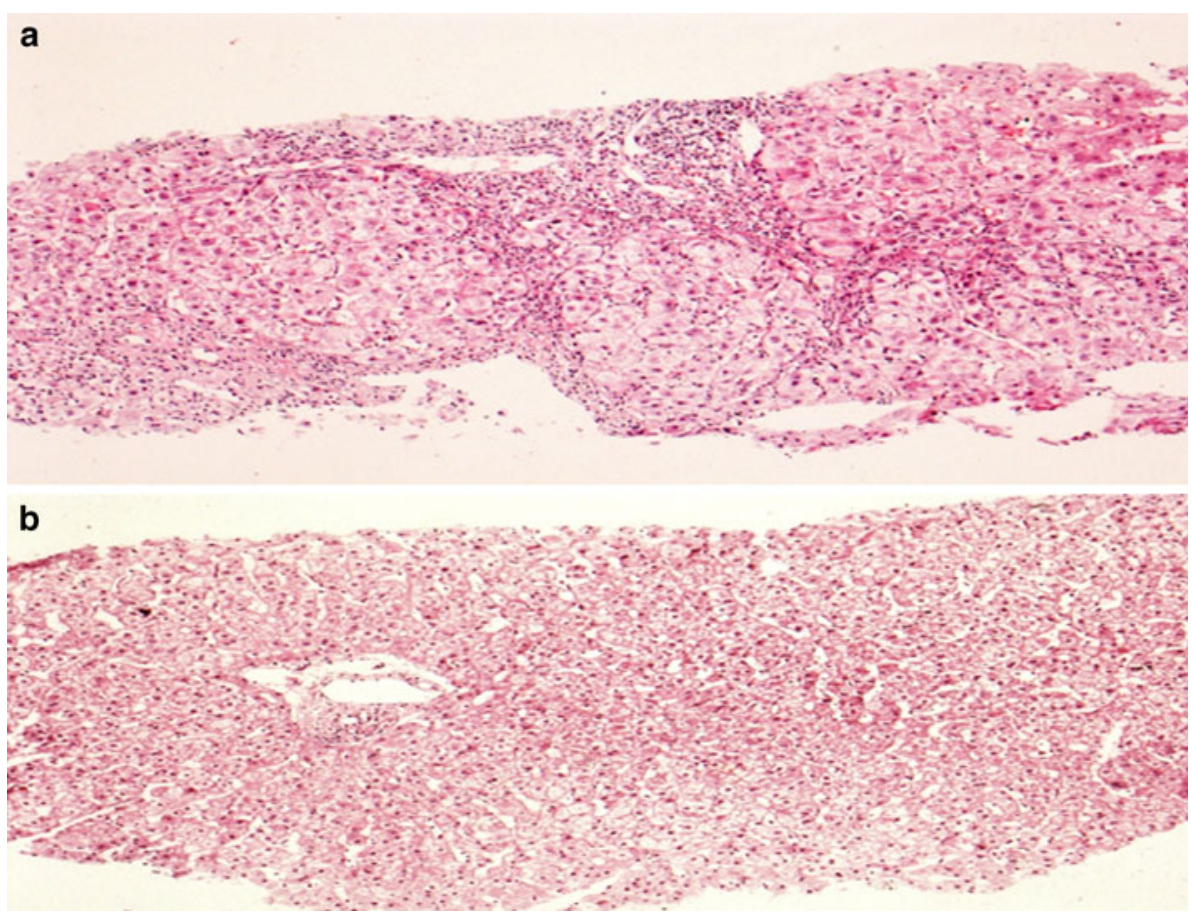

significant differences between monotherapy and combination therapy groups, demonstrating that the addition of liver protectant drug bicyclol to ADV antiviral therapy did not affect the ADV antiviral efficacy. Nevertheless, a significant histological improvement has been confirmed for both monotherapy and combination therapy groups. At the same time, this study clearly revealed that de novo combination of ADV plus bicyclol could achieve even better histological improvement for $\mathrm{HBeAg}$-positive $\mathrm{CHB}$ patients.

The advantage of using de novo combination of ADV and bicyclol could be seen as early as 12 weeks of therapy. From week 12, the rates of ALT and AST normalization for patients with combination therapy were significantly superior to that of patients on monotherapy. In combination with the more significant improvement in liver histology at the end of therapy and the safety profile of this de novo combination therapy, the result of this study convinced us for its value in exploring a better treatment regimen for CHB patients.

To finally establish a new strategy for patients with $\mathrm{CHB}$, a prolonged treatment and long-term follow-up are needed. The mechanism for potential drug interaction, treatment efficacy, and factors determining the efficacy of this combination therapy await further elucidation. Various combinations with different NUC and liver protectant drugs [32] are also the clinical interests in the future. Because of the limited number of cases included in this study, and comparatively short-term treatment, it is required to expand the sample size and extend the treatment duration to have firm conclusion. Optimized treatment course and long-term follow-up after cessation of the treatment are also important in future.

Open Access This article is distributed under the terms of the Creative Commons Attribution Noncommercial License which permits any noncommercial use, distribution, and reproduction in any medium, provided the original author(s) and source are credited.

\section{References}

1. Custer B, Sullivan SD, Hazlet TK, et al. Global epidemiology of hepatitis B virus. J Clin Gastroenterol 2004;38:S158-S168

2. Mendy ME, Welzel T, Lesi OA, et al. Hepatitis B viral load and risk for liver cirrhosis and hepatocellular carcinoma in The Gambia, West Africa. J Viral Hepat 2010;17:115-122

3. Lok AS, McMahon BJ. Chronic hepatitis B. Hepatology 2007;45: 507-539

4. Dan YY, Aung MO, Lim SG. The economics of treating chronic hepatitis B in Asia. Hepatol Int 2008;2:284-295

5. Liu S, Zhang $\mathrm{H}, \mathrm{Gu} \mathrm{C}$, et al. Associations between hepatitis B virus mutations and the risk of hepatocellular carcinoma: a metaanalysis. J Natl Cancer Inst 2009;101:1066-1082

6. Sylvan SP, Hellstrom UB. Modulation of serum interleukin-18 concentrations and hepatitis B virus DNA levels during interferon therapy in patients with hepatitis B e-antigen-positive chronic hepatitis B. J Interferon Cytokine Res 2010;30:901-908

7. Wolters LM, Niesters HG, de Man RA, et al. Nucleoside analogues for chronic hepatitis B. Eur J Gastroenterol Hepatol 2001;13:1499-1506

8. Dakin H, Bentley A, Dusheiko G. Cost-utility analysis of tenofovir disoproxil fumarate in the treatment of chronic hepatitis B. Value Health 2010;13:922-933

9. Schif ER, Lai CL, Hadziyannis S, et al. Adefovir dipivoxil therapy for lamivudine-resistant hepatitis B in pre-and post-liver transplantation patients. Hepatology 2003;38:1419-1427 
10. Marcellin P, Cadranel JF, Fontanges T, et al. High rate of adefovir-lamivudine combination therapy in nucleoside-naïve patients with chronic hepatitis B in France: results of a national survey in 1730 patients. Eur J Gastroenterol Hepatol 2010;22:1290-1296

11. Upadhyaya N, Chang R, Davis C, et al. Chronic hepatitis B: perceptions in Asian American communities and diagnosis and management practices among primary care physicians. Postgrad Med 2010;122:165-175

12. Chang TT, Liaw YF, Wu SS, et al. Long-term entecavir therapy results in the reversal of fibrosis/cirrhosis and continued histological improvement in patients with chronic hepatitis B. Hepatology 2010;52:886-893

13. Tak WY, Park SY, Cho CM, et al. Clinical, biochemical, and pathological characteristics of clevudine-associated myopathy. J Hepatol 2010;53:261-266

14. Hadziyannis SJ, Tassopoulos NC, Heathcote EJ, et al. Long-term therapy with adefovir dipivoxil for HBeAg-negative chronic hepatitis B. N Engl J Med 2005;352:2673-2681

15. Marcellin P, Chang TT, Lim SG, et al. Adefovir dipivoxil for the treatment of hepatitis B e antigen-positive chronic hepatitis B. N Engl J Med 2003;348:808-816

16. Ryu HJ, Lee JM, Ahn SH, et al. Efficacy of adefovir add-on lamivudine rescue therapy compared with switching to entecavir monotherapy in patients with lamivudine-resistant chronic hepatitis B. J Med Virol 2010;82:1835-1842

17. Freedman ND, Curto TM, Morishima C, et al. Silymarin use and liver disease progression in the hepatitis $\mathrm{C}$ antiviral long-term treatment against cirrhosis trial. Aliment Pharmacol Ther 2011;33:127-137

18. Lin A, Chen J, Liu Y, et al. Preparation and evaluation of $N$-caproyl chitosan nanoparticles surface modified with glycyrrhizin for hepatocyte targeting. Drug Dev Ind Pharm 2009;35: $1348-1355$

19. Liu GT, Li Y, Wei HL, et al. Mechanism of protective action of bicyclol against $\mathrm{CCl}_{4}$-induced liver injury in mice. Liver Int 2005;25:872-879

20. Bao XQ, Liu GT. Involvement of HSP70 in the protection of bicyclol on apoptosis of HepG2 cells intoxicated by D-galactosamine. J Asian Nat Prod Res 12:313-323

21. Lou XE, Xu N, Yao HP, et al. Bicyclol attenuates pro-inflammatory cytokine and chemokine productions in CpG-DNA- stimulated L02 hepatocytes by inhibiting p65-NF-kappaB and p38-MAPK activation. Pharmazie 2010;65:206-212

22. Yu YN, Chen H, Li Y. Effect of bicyclol on cisplatin-induced hepatotoxicity in the hepatocarcinoma 22 tumour-bearing mice. Basic Clin Pharmacol Toxicol 2009;104:300-305

23. Bao XQ, Liu GT. Induction of overexpression of the 27-and $70-\mathrm{kDa}$ heat shock proteins by bicyclol attenuates concanavalin A-induced liver injury through suppression of nuclear factorkappaB in mice. Mol Pharmacol 2009;75:1180-1188

24. Sun H, Liu GT. Inhibitory effect of anti-hepatitis drug bicyclol on invasion of human hepatocellular carcinoma MHCC97-H cells with high metastasis potential and its relative mechanisms. J Asian Nat Prod Res 2009;11:576-583

25. Knodell RG, Ishak KG, Black WC, et al. Formulation and application of a numerical scoring system for assessing histological activity in asymptomatic chronic active hepatitis. Hepatology 1981;1:431-435

26. Westland CE, Yang H, Delaney WE, et al. Activity of adefovir dipivoxil against all patterns of lamivudine-resistant hepatitis $B$ viruses in patients. J Viral Hepatitis 2005;12:67-73

27. Minde Z, Yimin M, Guangbi Y, et al. A double-blind randomized trial of adefovir dipivoxil in Chinese subjects with $\mathrm{HBeAg}$ positive chronic hepatitis B. Hepatology 2006;43:108-116

28. Kim HJ, Park JH, Park DI, et al. Rescue therapy for lamivudineresistant chronic hepatitis B: comparison between entecavir $1.0 \mathrm{mg}$ monotherapy, adefovir monotherapy and adefovir add-on lamivudine combination therapy. J Gastroenterol Hepatol 2006;25: $1374-1380$

29. Li M, Liu GT. Inhibition of Fas/FasL mRNA expression and TNF- $\alpha$ release in concanavalin A-induced liver injury in mice by bicyclol. World J Gastroenterol 2004;10:1775-1779

30. Liu GT. Bicyclol: a novel drug for treating chronic viral hepatitis B and C. Med Chem 2009;5:29-43

31. Liu Geng Tao. Bicyclol: A novel drug for treating chronic viral hepatitis B and C. Med Chem 2009;5:29-43

32. Bao XQ, Liu GT. Bicyclol protects HepG2 cells against Dgalactosamine-induced apoptosis through inducing heat shock protein 27 and mitochondria associated pathway. Acta Pharmacol Sin 2010;31:219-226 